\title{
BMPÍIULO VI
}

OSERUIBO DE GONUUUENGHA FORTALEOMLENTO DE VÍLGULOS PARA GRALNGAS E ADOLESGENTIES DE NO GONIEKTIO DO SISTERM

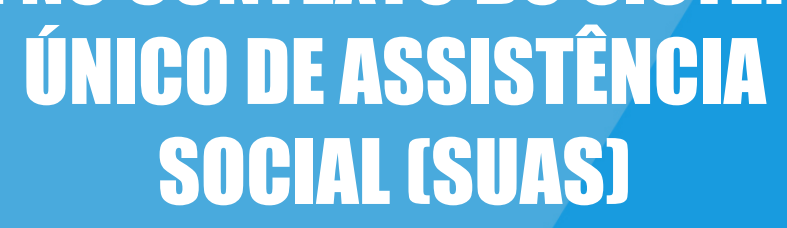

DOI: http://dx.doi.org/10.18616/estadodir16

André Viana Custódio Ismael Francisco de Souza

SUMÁRIO 


\section{INTRODUÇÃO}

Este artigo aborda as características do Serviço de Convivência e Fortalecimento de Vínculos para crianças e adolescentes com de 6 a 15 anos no contexto do Sistema Único de Assistência Social (SUAS); analisa as diretrizes da Política Nacional de Assistência Social (PNAS) nas dimensões de Proteção Social Básica e proteção social especial; nas ações para gestão do sistema, nos requisitos da norma operacional básica de recursos humanos e do protocolo de gestão integrada de serviços, benefícios e transferência de renda; estuda a tipificação nacional dos serviços socioassistenciais e os procedimentos do Serviço de Convivência e Fortalecimento de Vínculos em fase de implantação no Brasil. O método de abordagem foi o hipotético dedutivo e o método de procedimento monográfico com pesquisa em bases de dados de legislação.

\section{POLÍTICA NACIONAL DE ASSISTÊNGIA SOCIAL [PNAS]}

A PNAS encontra suas raízes históricas e fundamentos na Lei Orgânica da Assistência Social (LOAS), que decorre da garantia constitucional prevista no art. 194 a qual estabelece que

Art. 194 - A seguridade social compreende um conjunto integrado de ações de iniciativa dos Poderes Públicos e da sociedade, destinadas a assegurar os direitos relativos à saúde, à previdência e à assistência social.

Parágrafo Único - Compete ao Poder Público, nos termos da lei, organizar a seguridade social, com base nos seguintes objetivos:

I - universalidade da cobertura e do atendimento;

II - uniformidade e equivalência dos benefícios e serviços às populações urbanas e rurais;

III - seletividade e distributividade na prestação dos benefícios e serviços; 
IV - irredutibilidade do valor dos benefícios;

$\mathrm{V}$ - equidade na forma de participação no custeio;

$\mathrm{VI}$ - diversidade da base de financiamento. (BRASIL, 1988).

Assim, a assistência social foi definitivamente reconhecida como um direito do cidadão e dever do estado com os objetivos de proteção à família, à maternidade, à infância, à adolescência e à velhice, a garantia de proteção e integração ao mercado de trabalho, a proteção e o atendimento às pessoas com deficiência, bem como a garantia de benefícios àqueles que enfrentam as condições de pobreza com vistas à universalização dos direitos sociais básicos.

Nesse contexto, são considerados como princípios da Assistência Social:

I - supremacia do atendimento às necessidades sociais sobre as exigências de rentabilidade econômica;

II - universalização dos direitos sociais, a fim de tornar o destinatário da ação assistencial alcançável pelas demais políticas públicas;

III - respeito à dignidade do cidadão, à sua autonomia e ao seu direito a benefícios e serviços de qualidade, bem como à convivência familiar e comunitária, vedando-se qualquer comprovação vexatória de necessidade;

IV - igualdade de direitos no acesso ao atendimento, sem discriminação de qualquer natureza garantindo-se equivalência às populações urbanas e rurais;

$V$ - divulgação ampla dos benefícios, serviços, programas e projetos assistenciais, bem como dos recursos oferecidos pelo Poder Público e dos critérios para sua concessão. (BRASIL, 1993)

Para concretizar os princípios básicos da Assistência Social, foi instituída a PNAS, em 15 de outubro de 2004. A PNAS veio consolidar o sistema 
de proteção social brasileiro como uma das dimensões da Seguridade Social conjuntamente com saúde e previdência social. O desafio para implementação desse novo campo de políticas públicas é justamente a transição de uma concepção de proteção social àqueles que dela necessitam para o reconhecimento da assistência social como um direito fundamental em consonância com os compromissos internacionais brasileiros relativos aos direitos humanos. Seu caráter essencial não contributivo acentua a responsabilidade do Estado em garantir a proteção social essencial à garantia universal de desenvolvimento humano.

A implantação da PNAS e do SUAS tem liberado, em todo o território nacional, forças políticas que, não sem resistência, disputam a direção social da assistência social na perspectiva da justiça e dos direitos que ela deve consagrar, a partir das profundas alterações que propõe nas referências conceituais, na estrutura organizativa e na lógica de gestão de controle das ações na área. (COUTO et al., 2010, p. 38).

Seus fundamentos principiológicos estão assentados no marco da Constituição da República Federativa do Brasil e na LOAS. A visão social de proteção constituída, a partir daí, envolve necessariamente o reconhecimento dos riscos e vulnerabilidades sociais e o estabelecimento de estratégias políticas para o seu enfrentamento. Além disso, considera a necessidade do reconhecimento das diferenças incorporando o princípio da diversidade social e individual como fatores significativos para a proteção e a autonomia. Rompe, portanto, com uma concepção histórica discriminatória e estigmatizante que traduzia as condições sociais e subjetivas pela via do avesso, nas quais as marcas principais estabeleciam-se pela via do negativo, das impossibilidades e da arcaica visão das irregularidades.

Os princípios norteadores da PNAS incorporam as disposições estabelecidas na LOAS. A organização da PNAS está vinculada às diretrizes fundamentais da descentralização político-administrativa, da participação 
popular, da primazia da responsabilidade do Estado na condução da política e na centralidade da família.

A descentralização político-administrativa conduz ao compartilhamento de responsabilidades entre as respectivas esferas de governo considerando-se as diferenças e características socioterritoriais locais, aonde deve acontecer a participação popular na formulação e no controle das ações. Deve-se considerar ainda que "[...] a implementação de políticas públicas é caracterizada pelo dilema de assegurar a integridade política e autonomia dos diversos níveis de governo e, simultaneamente, coordenar ações para alcançar fins comuns." (PALOTTI; COSTA, 2020).

Ao se designar a primazia da responsabilidade do Estado no âmbito da política de assistência social, enfatiza-se o aspecto da essencialidade no estabelecimento de uma política que tenha caráter de política de Estado com permanência e continuidade com capacidade de acesso universal focalizada na família, à qual se constituiu como elemento central na concepção e implementação de serviços, programas, projetos e benefícios (BRASIL, 2009d).

A opção pela família justifica-se:

Importante citar também que os problemas experimentados e vividos pelas famílias são, quase em sua totalidade, resultados da realidade em que vivem. Ou seja, a questão social interfere e modifica as relações e dinâmicas familiares - relatos dos profissionais que desenvolvem trabalho social com famílias no âmbito do Sistema Único de Assistência Social (Suas) e estudos e pesquisas apontam tal fato. Por outro lado, a família está vinculada a uma rede de laços que vão para além do seu bairro. Assim, as famílias enfrentam dificuldades relacionadas ao contexto social e à situação de acesso precário a serviços, mas, ao se desenvolver trabalho social com as famílias, não se pode negligenciar a rede de laços que se faz no cotidiano e que funciona como elemento de potencialidade para o trabalho social. (ANDRADE; MATIAS, 2009, p. 220) 
Dos objetivos iniciais quando da formulação da política de assistência social, observa-se preocupação especial com o provimento de serviços e benefícios de modo atender as necessidades da família, garantindo o acesso aos bens e serviços socioassistenciais referenciados de acordo com a territorialidade como forma de garantir as condições básicas para o fortalecimento da convivência familiar e comunitária.

A Política Pública de Assistência Social está embasada nas proteções afiançadas consideradas como Proteção Social Básica e Proteção Social Especial.

\section{Proteção Social Básica}

A Proteção Social Básica visa prevenir situações de risco e vulnerabilidades investindo no desenvolvimento de potencialidades e oferecendo a possibilidade de aquisições individuais e coletivas. Tem como referência especial as condições de vulnerabilidade social decorrente da situação de pobreza, privação e fragilização dos vínculos afetivos. Está articulado no âmbito do SUAS, operacionalizado diretamente por intermédio dos Centros de Referência da Assistência Social (CRAS) e indiretamente nas entidades e organizações de assistência social, com programas e serviços específicos de atendimento direto à família como é o caso do Programa de Atenção Integral à Família (PAIF) (BRASIL, 2009d).

O Centro de Referência da Assistência Social - CRAS é uma unidade pública estatal de base territorial, localizado em áreas de vulnerabilidade social, que abrange a um total de até 1.000 famílias/ano. Executa serviços de proteção social básica, organiza e coordena a rede de serviços sócio-assistenciais locais da política de assistência social. (BRASIL, 2009d, p. 35).

Além disso, o CRAS tem por atribuição realizar o mapeamento e a organização da rede socioassistencial de proteção básica e promover a 
inserção das famílias nos serviços de assistência social, de acordo com as orientações do gestor municipal da Assistência Social e, também, conforme as diretrizes estabelecidas pelos mecanismos de controle e monitoramento da política. Para garantir o alcance de suas ações deve considerar aspectos relevantes, como a intersetorialidade das ações, a sustentabilidade, a ruptura do ciclo intergeracional de exclusão social (BRASIL, 2009d).

Segundo a PNAS,

São considerados serviços de proteção básica de assistência social aqueles que potencializam a família como unidade de referência, fortalecendo seus vínculos internos e externos de solidariedade, através do protagonismo de seus membros e da oferta de um conjunto de serviços locais que visam a convivência, a socialização e o acolhimento em famílias cujos vínculos familiar e comunitário não foram rompidos [...] (BRASIL, 2009d, p. 36).

A Tipificação Nacional de Serviços Socioassistenciais, a Proteção Social Básica envolve os serviços de PAIF, de Convivência e Fortalecimento de Vínculos e de Proteção Social Básica no domicílio para pessoas com deficiência e idosas (BRASIL, 2009b).

\section{Proteção Social Especial}

A proteção social especial caracteriza-se como modalidade de atendimento assistencial que atenta às situações de risco pessoal e social, decorrente das variadas formas de violação dos direitos humanos, como o abandono, maus tratos, abuso sexual, uso de substâncias psicoativas, situação de rua, prática de ato infracional, exploração do trabalho infantil e inúmeras outras, apontam para a necessidade de atendimento especializado. Seu caráter especializado indica a necessidade de acompanhamento individualizado e ênfase maior no aspecto protetivo das ações (BRASIL, 2009c). 
Nesse contexto, estabelecem-se os Centros de Referência Especializados da Assistência Social que atuam nos níveis de Média e Alta Complexidade.

Os serviços considerados de média complexidade são

[...] aqueles que oferecem atendimentos às famílias e indivíduos com seus direitos violados, mas cujos vínculos familiar e comunitário não foram rompidos. Neste sentido, requerem maior estruturação técnico-operacional e atenção especializada e mais individualizada, e, ou, acompanhamento sistemático e monitorado [...] (BRASIL, 2009d, p.38).

Para a Tipificação Nacional de Serviços Socioassistenciais são considerados como serviços de média complexidade:

a. Serviço de Proteção e Atendimento Especializado a Famílias e Indivíduos (PAEFI);

b. Serviço Especializado em Abordagem Social;

c. Serviço de Proteção Social a Adolescentes em Cumprimento de Medida Socioeducativa de Liberdade Assistida (LA), e de Prestação de Serviços à Comunidade (PSC);

d. Serviço de Proteção Social Especial para Pessoas com Deficiência, Idosas e suas Famílias;

e. Serviço Especializado para Pessoas em Situação de Rua. (BRASIL, 2009b, p. 3).

Já os serviços considerados de Alta Complexidade "[...] são aqueles que garantem proteção integral - moradia, alimentação, higienização e trabalho protegido para famílias e indivíduos que se encontram sem referência e, ou, em situação de ameaça, necessitando ser retirados de seu núcleo familiar e, ou, comunitário [...]." (BRASIL, 2009d. p. 38). 
A Tipificação Nacional de Serviços Socioassistenciais considera como serviços de Alta Complexidade:

a. Serviço de Acolhimento Institucional, nas seguintes modalidades: abrigo institucional; Casa-Lar; Casa de Passagem; Residência Inclusiva.

b. Serviço de Acolhimento em República;

c. Serviço de Acolhimento em Família Acolhedora;

d. Serviço de Proteção em Situações de Calamidades Públicas e de Emergências. (BRASIL, 2009b, p.4).

Desse modo, a Política Pública de Assistência Social procura alcançar uma visão emancipatória fundada no reconhecimento de direitos e da condição política de cidadania fortalecendo as capacidades e potencialidades como forma de atendimento às necessidades básicas de desenvolvimento humano. Por isso se estabeleceu que essa política deve considerar as pessoas, suas circunstâncias de vida e a família como um núcleo de apoio relacional.

\section{SISTEMA ÚNICO DE ASSISTÊNGIA SOCIAL [SUASI E A GESTÃo DA POLÍTICA NACIONAL DE ASSISTÊNGIA SOGIAL [PNAS]}

O SUAS organizou um modelo de gestão para a PNAS fundados nos princípios da descentralização e da participação visando à organização em todo o território nacional das ações socioassistenciais. Com base no princípio da responsabilidade da gestão compartilhada e do cofinanciamento das três esferas de governo define competências para cada um dos entes garantindo a participação da sociedade civil em todas as instancias de implantação e implementação do novo modelo.

O redesenho das ações socioassistenciais no âmbito do SUAS é estratégico para a resolução de contradições de alguns dos termos mais caros a concretização do direito 
a assistência social: a combinação entre os princípios da universalidade e da seletividade, a articulação das dimensões preventivas, especialmente protetivas da política pública de assistência social e a potencialização das ações emancipatórias coletivas, associadas ao desenvolvimento de relações personalizadas de (re) construção de novos projetos de vida dos indivíduos e famílias expostos ao processo de reprodução dos mecanismos que originaram sua condição de pobreza e de subalternização socioculturais. (PAIVA, 2006, p. 23).

Assim, o SUAS possibilita normatização dos padrões nos serviços, qualidade no atendimento, indicadores de avaliação e resultado e a nomenclatura dos serviços e da rede socioassistencial. Define, portanto, eixos estruturantes e de subsistema nos seguintes termos:

- Matricialidade Sociofamiliar.

- Descentralização político-administrativa e Territorialização.

- Novas bases para a relação entre Estado e Sociedade Civil.

- Financiamento.

- Controle Social.

- O desafio da participação popular/cidadão usuário.

- A Política de Recursos Humanos.

- A Informação, o Monitoramento e a Avaliação. (BRASIL, 2009d, p. 39).

A organização no SUAS dos serviços socioassistenciais tem como referência a vigilância social; a proteção social; e a defesa social e institucional. A vigilância social dedica-se

[...] à produção, sistematização de informações, indicadores e índices territorializados das situações de vul- 
nerabilidade e risco pessoal e social que incidem sobre famílias/pessoas nos diferentes ciclos da vida; pessoas com redução da capacidade pessoal, com deficiência ou em abandono; crianças e adultos, vítimas de formas de exploração, de violência e de ameaças; vítimas de preconceito por etnia, gênero e opção pessoal; vítimas de apartação social que lhes impossibilite sua autonomia e integridade, fragilizando sua existência; vigilância sobre os padrões de serviços de assistência social em especial aqueles que operam na forma de albergues, abrigos, residências, semi-residências, moradias provisórias para os diversos segmentos etários. Os indicadores a serem construídos devem mensurar no território as situações de riscos sociais e violação de direitos. (BRASIL, 2009d, p. 39-40).

A proteção social está vinculada às seguranças afiançadas que envolvem a segurança de sobrevivência ou de rendimento e de autonomia; a segurança de convívio ou vivência familiar; e a segurança e acolhida.

A defesa social e institucional está organizada para garantir acesso ao conhecimento dos direitos socioassistenciais e a sua respectiva defesa, em especial na garantia dos seguintes direitos:

- Direito ao atendimento digno, atencioso e respeitoso, ausente de procedimentos vexatórios e coercitivos;

- Direito ao tempo, de modo a acessar a rede de serviço com reduzida espera e de acordo com a necessidade;

- Direito à informação, enquanto direito primário do cidadão, sobretudo àqueles com vivência de barreiras culturais, de leitura, de limitações físicas;

- Direito do usuário ao protagonismo e manifestação de seus interesses;

- Direito do usuário à oferta qualificada de serviço;

- Direito de convivência familiar e comunitária. (BRASIL, 2009d, p. 40). 
O SUAS tem como referência a rede socioassistencial definida como um conjunto integrado de ações de iniciativa pública e da sociedade que ofertam e operam benefícios, serviços, programas e projetos, o que supõe a articulação entre todas essas unidades de provisão de proteção social sob a hierarquia de básica e especial e ainda por níveis de complexidade.

A gestão da Política Pública de Assistência Social tem com referência a implantação e funcionamento dos conselhos de Assistência Social, nas três esferas, com composição paritária entre governo e sociedade civil e a instituição dos Fundos de Assistência Social, que concentra os recursos para as políticas públicas da área, que são controlados pelo órgão gestor e fiscalizados pelos conselhos de acordo com os Planos de Assistência Social.

Outro aspecto relevante na gestão da Assistência Social é aquele referente à participação dos próprios usuários dos serviços socioassistenciais. Nesse sentido,

[...] o desafio para a gestão do Suas é potencializar, nos espaços de atendimento às populações, atividades que desenvolvam a autonomia e o protagonismo dos usuários na direção de materializar a participação deles no espaço de controle social utilizando mecanismos de democratização da política. (COUTO, 2009, p. 207).

A NOB/SUAS define os níveis de gestão do SUAS como Gestão Inicial, Básica ou Plena, estabelecendo requisitos e incentivos para o aprimoramento do sistema. Também define as responsabilidades da União, dos Estados, do Distrito Federal e dos municípios relativas à gestão. Aponta critérios para a habilitação e desabilitação nos variados níveis de gestão, bem como os critérios e responsabilidades relativos ao cofinanciamento, condições para transferência de recursos entre os entes e critérios de partilhas de recursos, dentre outros aspectos relativos ao financiamento do Sistema Único da Assistência Social. 
A Norma Operacional Básica de Recursos Humanos do SUAS (NOBRH/SUAS) considerando a necessidade de uma política de valorização e qualificação da gestão do trabalho no âmbito do SUAS requer o conhecimento acentuado dos profissionais que atuam na assistência social, bem como na capacidade de concretização das estratégias políticas, por isso veio regulamentar ações e fortalecer a atuação profissional desses agentes. Assim, definiu que deve ser considerado na gestão do trabalho na área da assistência social:

- Princípios e Diretrizes Nacionais para a gestão do trabaIho no âmbito do SUAS;

- Princípios Éticos para os Trabalhadores da Assistência Social;

- Equipes de Referência;

- Diretrizes para a Política Nacional de Capacitação;

- Diretrizes Nacionais Para os Planos de Carreira, Cargos e Salários;

- Diretrizes para Entidades e Organizações de Assistência Social.

- Diretrizes para o co-financiamento da Gestão do trabalho;

- Responsabilidades e Atribuições do Gestor Federal, dos Gestores Estaduais, do Gestor do Distrito Federal dos Gestores Municipais para a Gestão do Trabalho no âmbito do SUAS;

- Organização do Cadastro Nacional de Trabalhadores do SUAS - Módulo CADSUAS;

- Controle Social da Gestão do Trabalho no âmbito do SUAS;

- Regras de Transição. (BRASIL, 2006, p.10).

Desse modo, destaca como princípios e diretrizes nacionais para a gestão do trabalho no âmbito do SUAS o caráter público da prestação dos serviços socioassistenciais com servidores responsáveis pela sua execução; a preenchimento de cargos criados por lei para suprir as necessidades dos 
serviços, conforme os Planos de Assistência Social; a preocupação com uma política nacional de capacitação.

A NOB-RH/SUAS estabelece o conceito de equipes de referência como base para a realização dos trabalhos no âmbito do SUAS definindo como:

Equipes de referência são aquelas constituídas por servidores efetivos responsáveis pela organização e oferta de serviços, programas, projetos e benefícios de proteção social básica e especial, levando-se em consideração o número de famílias e indivíduos referenciados, o tipo de atendimento e as aquisições que devem ser garantidas aos usuários. (BRASIL, 2006, p.14).

No âmbito da Proteção Social Básica, a composição da equipe de referência dos CRASs leva em consideração o porte dos municípios estabelecendo como de pequeno porte I aqueles com até 2.500 famílias referenciadas; de pequeno porte II os municípios com até 3.500 famílias referenciadas e; médio e grande porte, incluindo metrópole e o Distrito Federal aqueles com 5.000 famílias referenciadas.

As equipes dos CRASs devem contar sempre com um coordenador, com formação superior, concursado e com experiência em gestão na área e em trabalhos comunitários. Já as equipes para os municípios classificados como pequeno porte I devem contar com dois técnicos de nível superior, sendo um assistente social e outro preferencialmente psicólogo e dois técnicos de nível médio. Nos municípios classificados como pequeno porte II há exigência de pelo menos três técnicos de nível superior, sendo dois assistentes sociais e preferencialmente um psicólogo e três técnicos de nível médio. Nos casos dos municípios de médio e grande porte, metrópoles e do Distrito Federal são exigidos quatro técnicos de nível superior, sendo dois profissionais assistentes sociais, um psicólogo, um profissional que compõe o SUAS e quatro técnicos de nível médio (BRASIL, 2006). 
Já na Proteção Social Especial, as equipes de referência para a composição do Centro de Referência Especializado de Assistência Social (CREAS), constituído como pólo que articula e coordena a proteção social especial, tem como referência os níveis de complexidade do atendimento especializado.

\begin{abstract}
Alguns serviços, como os de média e alta complexidade, alinhados à proteção social especial, podem não ser estruturados apenas na escala dos municípios, ou porque não possuem em seu território condições de oferecê-los ou porque já existem municípios que ofertam, por intermédio de consórcios (como municípios pólos) os serviços de referência regional, garantindo o atendimento de seus usuários e dos usuários dos municípios vizinhos. Esses serviços podem, ainda, ser oferecidos pelo órgão gestor estadual. A concepção de serviços territorializados no SUAS requer, assim, gestão cooperada e compartilhada entre os três entes federados. (ALBUQUERQUE; CRUS, 2012).
\end{abstract}

No atendimento de média complexidade, as exigências variam de acordo com o nível de gestão da assistência social. Nos municípios com gestão inicial e básica, o CREAS necessita de um coordenador, um assistente social, um psicólogo, um advogado, dois profissionais de nível superior ou médio para trabalhar na abordagem dos usuários e um auxiliar administrativo. Nos municípios com gestão plena e os Estados que mantém serviços regionalizados, é necessário um coordenador, dois assistentes sociais, dois psicólogos, um advogado, quatro profissionais de nível superior ou médio para a abordagem dos usuários e dois auxiliares administrativos (BRASIL, 2006).

No atendimento de Alta Complexidade, as equipes de referência são definidas conforme as características específicas do serviço envolvendo profissionais específicos de acordo as modalidade de atendimento definidas como: atendimento em pequenos grupos (abrigo institucional, casa-lar e casa de passagem) com equipe de referência para atendimento direto e equipe de referência vinculada ao órgão gestor para atendimento psicossocial; família 
acolhedora ou república com equipe de atendimento psicossocial vinculada ao órgão gestor; instituições de longa permanência para idosos com equipe de referência para atendimento direto (BRASIL, 2006).

A Norma operacional básica de recursos humanos (NOB-RH) SUAS) estabelece um quadro de referência de profissionais responsáveis pela gestão do sistema. No que se refere à gestão municipal considera como funções essenciais: Gestão do Sistema Municipal de Assistência Social; Coordenação da Proteção Social Básica; Coordenação da Proteção Social Especial; Planejamento e Orçamento; Gerenciamento do Fundo Municipal de Assistência Social; Gerenciamento dos Sistemas de Informação; Monitoramento e Controle da Execução dos Serviços, Programas, Projetos e Benefícios; Monitoramento e Controle da Rede Socioassistencial; Gestão do Trabalho e Apoio às Instâncias de Deliberação.

$O$ quadro de referência para a gestão estadual tem como funções essenciais ao sistema: Gestão do Sistema Estadual de Assistência Social; Coordenação da Proteção Social Básica; Coordenação da Proteção Social Especial; Gerenciamento do Fundo Estadual de Assistência Social; Gerenciamento dos Sistemas de Informação; Monitoramento e Controle da Execução dos Serviços, Programas, Projetos e Benefícios; Cooperação Técnica/ Assessoria aos Municípios; Gestão do Trabalho e Educação Permanente em Assistência Social (Capacitação); Apoio às Instâncias de Pactuação e Deliberação (BRASIL, 2006).

Já as funções essenciais na gestão federal implicam na garantia de atuação nos seguintes campos: Gestão do Sistema Único de Assistência Social; Coordenação da Proteção Social Básica; Coordenação da Proteção Social Especial; Coordenação de Gestão de Rendas e Benefícios; Planejamento e Orçamento; Gerenciamento do Fundo Nacional de Assistência Social; Monitoramento e Controle da Execução dos Serviços, Programas, Projetos e Benefícios; Gestão dos Sistemas de Informação; Apoio (cooperação/assessoria) à Gestão Descentralizada do SUAS; Gestão do Trabalho e Educação Permanente em Assistência Social (Capacitação); Apoio às Instâncias de Pactuação e Deliberação (BRASIL, 2006). 
A política nacional de capacitação dos trabalhadores da assistência social foi definida com base no compartilhamento de atribuições entre os governos federal, estaduais e municipais, com fundamento na concepção de educação permanente, que deve ser sistemática e continuada, sustentável, participativa, nacionalizada, descentralizada, avaliada e monitorada. Os plano anuais de capacitação são elaborados nas comissões intergestoras e deliberados nos conselhos de Assistência Social, tomando-se por referência:

a. a elaboração de diagnóstico de necessidades comuns de capacitação às diversas áreas de atuação;

b. o conhecimento do perfil dos trabalhadores e suas competências requeridas, considerando o padrão da prestação dos serviços desejado, considerando as informações obtidas no CADSUAS;

c. a definição de públicos, conteúdos programáticos, metodologia, carga horária e custos;

d. a inclusão de conteúdos relativos aos serviços, programas, projetos, benefícios e gestão da assistência social, bem como relativos a financiamento, planos, planejamento estratégico, monitoramento, avaliação, construção de indicadores e administração pública;

e. a especificidade dos trabalhos desenvolvidos com comunidades remanescentes de quilombos, povos indígenas e outras;

f. a definição de formas de monitoramento e avaliação dos próprios planos. (BRASIL, 2006, p. 18).

A NOB-RH/SUAS define diretrizes nacionais para os Planos de Carreira, Cargos e Salários (PCCS) que deverão ser incorporados em cada esfera de governo para os trabalhadores da assistência social baseados nos princípios da universalidade dos PCCS; equivalência dos cargos ou empregos; concurso público como forma de acesso à carreira; mobilidade do trabalhador; adequação funcional; gestão partilhada das carreiras, educação permanente, compromisso solitário e nos PCCS como instrumento de gestão. 
Sendo as entidades e organizações de assistência social instrumentos essenciais para a garantia do atendimento integral aos usuários, a NOB/ RH/SUAS define como diretrizes para as entidades e organizações:

1. valorizar seus trabalhadores de modo a ofertar serviços com caráter público e de qualidade conforme realidade do município;

2. elaborar e executar plano de capacitação em consonância com as diretrizes da Política Nacional de Capacitação;

3. viabilizar a participação de seus trabalhadores em atividades e eventos de capacitação e formação no âmbito municipal, estadual, distrital e federal na área de assistência social;

4. buscar, em parceria com o poder público, o tratamento salarial isonômico entre os trabalhadores da rede pública e da rede prestadora de serviços socioassistenciais;

5. manter atualizadas as informações sobre seus trabalhadores, disponibilizando-as aos gestores para a alimentação do Cadastro Nacional de Trabalhadores do SUAS. (BRASIL, 2006, p. 21).

É importante destacar que NOB-RH/SUAS ainda estabelece diretrizes para o cofinanciamento da gestão do trabalho; especifica as responsabilidades e atribuições dos gestores no âmbito do SUAS; bem como incentivos e requisitos para a gestão do trabalho no âmbito estadual, do Distrito Federal; e responsabilidades e atribuições dos gestores municipais de acordo com a modalidade de gestão.

Assim, com base na Norma Operacional Básica do SUAS (NOB) SUAS) e na PNAS, a Comissão Intergestores Tripartite emitiu o Protocolo de Gestão Integrada de Serviços, Benefícios e Transferências de Renda no âmbito do SUAS.

O referido protocolo destina-se à uniformização de procedimentos para a gestão integrada mediante a articulação dos serviços, benefícios e transferências de renda para o atendimento das famílias do Programa Bolsa 
Família, Programa de Erradicação do Trabalho Infantil e do Benefício de Prestação Continuada considerando como diretrizes a corresponsabilidade dos entes federados, as seguranças afiançadas pela PNAS e, em especial, a centralidade da família no atendimento socioassistencial como uma forma de garantia de direitos fundamentais; definindo como objetivos gerais:

a. Pactuar, entre os entes federados, os procedimentos que garantam a oferta prioritária de serviços socioassistenciais para as famílias beneficiárias do PBF, do PETI e famílias com beneficiário do BPC;

b. Construir possibilidades de atendimento intersetorial, qualificar o atendimento a indivíduos e famílias e potencializar estratégias para a inclusão social, o fortalecimento de vínculos familiares e comunitários, o acesso à renda e a garantia de direitos socioassistenciais;

c. Favorecer a superação de situações de vulnerabilidade e risco vividas pelas famílias beneficiárias do PBF, do PETI e do BPC, por meio da oferta de serviços socioassistenciais e encaminhamentos para a rede socioassistencial e das demais políticas públicas e, quando necessário, para órgãos do Sistema de Garantia de Direitos (SGD). (BRASIL, 2009a, p.9-10).

Nesse sentido, o Protocolo de Gestão Integrada definiu como objetivos específicos:

a. Adotar o Cadastro Único para Programas Sociais e o Cadastro do BPC como base de dados para a realização de diagnóstico de vulnerabilidade e risco no território;

b. Padronizar procedimentos de gestão para o atendimento das famílias mencionadas no Art. 1ㅇ;

c. Estabelecer fluxo de informações entre os entes federados no que diz respeito ao atendimento

d. das famílias; 
e. Padronizar procedimentos de gestão, instrumentos para a coleta de dados e geração de informações, indicadores para o monitoramento e a avaliação do atendimento das famílias;

f. Propor mecanismos que fortaleçam sistematicamente a articulação da rede socioassistencial,

g. de educação e saúde para monitorar e avaliar o atendimento das famílias beneficiárias de programas de transferência de renda, bem como a inclusão, o acesso e a permanência na escola dos beneficiários do PBF, PETI e BPC.. (BRASIL, 2009a, p. 10).

Para atingir os objetivos propostos no âmbito da PROTEÇÃO SOCIAL BÁSICA e da proteção social especial, o protocolo estabelece o compartilhamento e as responsabilidades específicas dos entes federados e dos conseIhos de Assistência Social, definindo competências no âmbito de cada uma das esferas de governo e as atribuições específicas em relação aos conselhos de Assistência Social.

O processo de operacionalização da gestão integrada dos serviços, benefícios e transferências de renda no âmbito do SUAS indica as competências e procedimentos no âmbito do Ministério do Desenvolvimento Social e do Combate à Fome (MDS), dos estados e dos municípios para a operacionalização do Programa Bolsa Família e do Programa de Erradicação do Trabalho Infantil (PETI). De igual modo, define as competências e procedimentos da União, dos estados e dos municípios na operacionalização do Benefício de Prestação Continuada da Assistência Social e os Benefícios Eventuais.

No que se refere ao monitoramento da gestão integrada, propõe indicadores para a avaliação da gestão no âmbito do Programa Bolsa Família, para a avaliação do atendimento das famílias beneficiárias do Programa Bolsa Família e do PETI e, inclusive, do atendimento às famílias com beneficiários do Benefício de Prestação Continuada e Benefícios Eventuais.

Nesse contexto, o Conselho Nacional de Assistência Social (CNAS) emitiu a Resolução n. 109, de 11 de novembro de 2009, que aprovou a 
Tipificação Nacional de Serviços Socioassistenciais, organizados por níveis de complexidade do SUAS, considerando a Proteção Social Básica e a Proteção Social Especial de Média e Alta Complexidade.

No âmbito da Proteção Social Básica, houve a tipificação do Serviço de Convivência e Fortalecimento de Vínculos com as seguintes características:

Serviço realizado em grupos, organizado a partir de percursos, de modo a garantir aquisições progressivas aos seus usuários, de acordo com o seu ciclo de vida, a fim de complementar o trabalho social com famílias e prevenir a ocorrência de situações de risco social. Forma de intervenção social planejada que cria situações desafiadoras, estimula e orienta os usuários na construção e reconstrução de suas histórias e vivências individuais e coletivas, na família e no território. Organiza-se de modo a ampliar trocas culturais e vivências, desenvolver o sentimento de pertença e de identidade, fortalecer vínculos familiares e incentivar socialização e a convivência comunitário. Possui caráter preventivo e proativo, pautado na defesa e na afirmação dos direitos e no desenvolvimento de capacidades e potencialidades, com vistas ao alcance de alternativas emancipatórias para o enfrentamento da vulnerabilidade social. (Brasil, 2009b, p. 9).

Trata-se de serviço articulado com o Serviço de Proteção e Atendimento Integral à Família (PAIF) ${ }^{1}$ visando promover o atendimento à família dos usuários desses serviços garantindo a matricialidade sociofamiliar da política de assistência social e tem como objetivos gerais:

1 "O Serviço de Proteção e Atendimento Integral à Família - PAIF" [integrante da Proteção Social Básica] "consiste em trabalho social com famílias, de caráter continuado, com a finalidade de fortalecer a função protetiva das famílias, prevenir a ruptura dos seus vínculos, promover seu acesso e usufruto de direitos e contribuir na melhoria de sua qualidade de vida. Prevê o desenvolvimento de potencialidades e aquisições das famílias e o fortalecimento de vínculos familiares e comunitários, por meio de ações de caráter preventivo, protetivo e proativo". (BRASIL, 2009b, p. 6). 
- Complementar o trabalho social com família, prevenindo a ocorrência de situações de risco social e fortalecendo a convivência familiar e comunitária;

- Prevenir a institucionalização e a segregação de crianças, adolescentes, jovens e idosos, em especial, das pessoas com deficiência, assegurando o direito à convivência familiar e comunitária; promover acessos a benefícios e serviços socioassistenciais, fortalecendo a rede de proteção social de assistência social nos territórios;

- Promover acessos a serviços setoriais, em especial políticas de educação, saúde, cultura, esporte e lazer existentes no território, contribuindo para o usufruto dos usuários aos demais direitos;

- Oportunizar o acesso às informações sobre direitos e sobre participação cidadã, estimulando o desenvolvimento do protagonismo dos usuários;

- Possibilitar acessos a experiências e manifestações artísticas, culturais e esportivas e de lazer, com vistas ao desenvolvimento de novas sociabilidades;

- Favorecer o desenvolvimento de atividades intergeracionais, propiciando trocas de experiências e vivencias, fortalecendo o respeito, a solidariedade e os vínculos familiares e comunitários. (Brasil, 2009b, p. 12).

O Serviço de Convivência e Fortalecimento de Vínculos deve prever o desenvolvimento de ações intergeracionais e a heterogeneidade na composição dos grupos por sexo, presença de pessoas com deficiência, etnia, raça entre outros.

O Serviço de Convivência e Fortalecimento de Vínculos está descrito conforme fases de desenvolvimento humano, considerando a geracionalidade, os períodos compreendidos entre: 1) Serviço para crianças de até 6 anos; Serviço para crianças e adolescentes de 6 a 15 anos; Serviço para adolescentes e jovens de 15 a 17 anos; e Serviço para idosos (Brasil, 2009b).

Os usuários do Serviço de Convivência e Fortalecimento de Vínculos para crianças e adolescentes de 6 a 15 anos e tem como usuários especiais àqueles: 
- [...] encaminhados pelos serviços de proteção social especial (Programa de Erradicação do Trabalho Infantil - PETI); serviço de proteção social especial a indivíduos e famílias; reconduzidas ao convívio familiar, após medida protetiva de acolhimento, e outros);

- $[\ldots .$.$] com deficiência, com prioridade para as beneficiá-$ rias do Benefício de Prestação Continuada (BPC);

- [...] cujas famílias são beneficiárias de programas de transferência de renda;

- [...] de famílias com precário acesso à renda e a serviços públicos e com dificuldades de manter. (Brasil, 2009b, p. 11).

Serviço de Convivência e Fortalecimento de Vínculos para crianças e adolescentes com idades entre 6 e 15 anos:

Tem por foco a constituição de espaço de convivência, formação para a participação e cidadania, desenvolvimento do protagonismo e da autonomia das crianças e adolescentes, a partir dos interesses, demandas e potencialidades dessa faixa etária. As intervenções devem ser pautadas em experiências lúdicas, culturais e esportivas como formas de expressão, interação, aprendizagem, sociabilidade e proteção social. Inclui crianças e adolescentes com deficiência, retirados do trabalho infantil ou submetidos a outras violações, cujas atividades contribuem para re-significar vivências de isolamento e de violação de direitos, bem como propiciar experiências favorecedoras do desenvolvimento de sociabilidades e na prevenção de situações de risco social. (Brasil, 2009, p. 10).

Nesse contexto, o referido serviço tem como objetivos específicos para esse período geracional: 
- Complementar as ações da família, e comunidade na proteção e desenvolvimento de crianças e adolescentes e no fortalecimento dos vínculos familiares e sociais;

- Assegurar espaços de referência para o convívio grupal, comunitário e social e o desenvolvimento de relações de afetividade, solidariedade e respeito mútuo;

- Possibilitar a ampliação do universo informacional, artístico e cultural dos jovens, bem como estimular o desenvolvimento de potencialidades, habilidades, talentos e propiciar sua formação cidadã;

- Propiciar vivências para o alcance de autonomia e protagonismo social;

- Estimular a participação na vida pública do território e desenvolver competências para a compreensão crítica da realidade social e do mundo contemporâneo;

- Possibilitar o reconhecimento do trabalho e da educação como direito de cidadania e desenvolver conhecimentos sobre o mundo do trabalho e competências específicas básicas;

- Contribuir para a inserção, reinserção e permanência do jovem no sistema educacional. (Brasil, 2009b, p. 13).

A tipificação elegeu como o trabalho social essencial a esse serviço: Acolhida; Orientação e encaminhamentos; Grupos de convívio e fortalecimento de vínculos; Informação, comunicação e defesa de direitos; Fortalecimento da função protetiva da família; Mobilização e fortalecimento das redes sociais de apoio; Informação; Banco de dados de usuários e organizações; Elaboração de relatórios e/ou prontuários; Desenvolvimento do convívio familiar e comunitário; e a Mobilização para a cidadania.

Para tanto, faz-se necessário o provimento de ambiente físico com sala(s) de atendimento individualizado, sala(s) de atividades coletivas e comunitárias e instalações sanitárias com adequada iluminação, ventilação, conservação, privacidade, salubridade, limpeza e acessibilidade em todos os seus ambientes de acordo com as normas da $A B N T$, bem como materiais permanentes e de consumo necessário ao desenvolvimento do serviço, como: 
mobiliário, computadores e outros. São necessários materiais socioeducativos, como artigos pedagógicos, culturais e esportivos; bando de dados de usuários(as) de benefícios e serviços socioassistenciais; banco de dados dos serviços socioassistenciais; Cadastro Único dos Programas Sociais, Cadastro de Beneficiários do BPC. Os recursos humanos devem atender as determinações da NOBRH/SUAS.

As aquisições pretendidas para os usuários consideram as seguranças da PNAS, em especial a Segurança de Acolhida, a Segurança do Convívio Familiar e Comunitário - Geral e a Segurança de Desenvolvimento da Autonomia - Geral.

Para crianças e adolescentes com idades de 6 a 15 anos, as atividades são oferecidas em dias úteis, feriados ou finais de semana, em turnos diários de até quatro horas. No caso de crianças e adolescentes retiradas do trabalho infantil, o serviço socioeducativo é, obrigatoriamente, de três horas diárias e constitui condicionalidade para transferência de renda às famílias.

O serviço é destinado aos usuários territorialmente referenciados aos CRASs por procura espontânea; por busca ativa; por encaminhamento da rede socioassistencial ou por encaminhamento das demais políticas públicas atendidos nas próprias unidades dos CRASs ou em centros da criança, adolescente, juventude e idosos referenciados aos CRAS.

A articulação em rede dá-se por meio dos serviços socioassistenciais de proteção social básica e proteção social especial; serviços públicos locais de educação, saúde (em especial, programas e serviços de reabilitação), cultura, esporte e, meio-ambiente e outros conforme necessidades; Conselhos de políticas públicas e defesa de direitos de segmentos específicos; Redes sociais; Instituições de ensino e pesquisa; Conselho Tutelar; Programas e projetos de desenvolvimento de talentos e capacidades.

O serviço espera gerar impacto social contribuindo para redução da ocorrência de situações de vulnerabilidade social; prevenção da ocorrência de riscos sociais, seu agravamento ou reincidência; aumento de acessos a serviços socioassistenciais e setoriais; ampliação do acesso aos direitos socioassistenciais e a melhoria da qualidade de vida dos usuários e suas famílias. 


\section{CONGLUSÃO}

O Serviço de Convivência e Fortalecimento de Vínculos para crianças e adolescentes de 6 a 15 anos vem preencher uma importante lacuna no contexto das políticas socioassistenciais fomentando ações de desenvolvimento integral para crianças e adolescentes no contraturno escolar e ampliando as oportunidades de desenvolvimento social, político e comunitário.

A universalização do serviço requer a compreensão dos serviços socioassistenciais como integrantes do conjunto de Direitos Humanos e, portanto, passível de exigibilidade por todos àqueles que necessitem.

Além disso, a oferta do serviço tende a qualificação às políticas de atendimento integral à crianças e adolescentes, com prioridade inclusive àquelas afastadas do trabalho infantil ou de outras condições de violação de direitos. A participação da comunidade e das famílias na gestão e melhoria do serviço é um dos desafios no aprofundamento das práticas democráticas de participação nas políticas públicas brasileiras.

O enfoque especializado na condição geracional é um ponto-chave que merece atenção especial dos gestores de modo a garantir um serviço adequado às necessidades e condições de desenvolvimento humano de crianças e adolescentes brasileiros.

\section{REFERÊNGIAS}

ALBUQUERQUE, Simone Aparecida; CRUS, José ferreira da. Um Sistema único de Assistência Social para o Brasil. In: TAPAJÓS, Luziele; RODRIGUES, Roberto Wagner da Silva. (org.). Rede SUAS: gestão e sistema de informação para o Sistema Único de Assistência Social. Brasília, DF: Secretaria Nacional de Assistência Social, 2007. p. 12-21. Disponível em: http://www.mds.gov.br/. Acesso em: 23 abr. 2020. 
ANDRADE, Priscilla Maia de; MATIAS, Mariana López. Notas sobre o desenvolvimento do trabalho social com famílias no âmbito da política de Assistência Social. In: MINISTÉRIO DO DESENVOLVIMENTO SOCIAL E COMBATE À FOME (MDS). UNESCO. Concepção e gestão da proteção social não contributiva no Brasil. Brasília, DF: Ministério do Desenvolvimento Social e Combate à Fome, UNESCO, 2009. Disponível em: http://www.mds.gov.br. Acesso em: 23 abr. 2020.

BRASIL. [Constituição (1988)]. Constituição da República Federativa do Brasil de 1988. Emendas Constitucionais de Revisão. Brasília, DF: Presidência da República, 1988. Disponível em: http://www.planalto.gov.br/ccivil_03/ Constituicao/Constituicao.htm. Acesso em: 26 jun. 2019.

BRASIL. Lei n. 8.742, de 7 de dezembro de 1993. Dispõe sobre a Organização da Assistência Social e dá outras providências. Brasília, DF: Presidência da República, 1993. Disponível em: http://www.planalto.gov.br/ccivil_03/Leis/ L8742.htm. Acesso em: 31 mar. 2021.

BRASIL. Ministério do Desenvolvimento Social e do Combate à Fome (MDS). Comissão Intergestores Tripartite. Resolução Cit n. 7, de 10 de setembro de 2009. Protocolo de Gestão Integrada de Serviços, Benefícios e Transferências de Renda no âmbito do Sistema Único de Assistência Social (SUAS). Brasília, DF: CIT, 2009a.

BRASIL. Ministério do Desenvolvimento Social e do Combate à Fome (MDS) Conselho Nacional de Assistência Social (CNAS). Resolução n. 109, de 11 de novembro de 2009. Tipificação Nacional de Serviços Socioassistenciais. Brasília, DF: MDS, 2009b.

BRASIL. Ministério do Desenvolvimento Social e do Combate à Fome (MDS). Secretaria de Avaliação e Gestão da Informação. In: Ministério do Desenvolvimento Social e Combate à Fome (MDS). Herkenhoff\&Prates - Tecnologia e Desenvolvimento. Secretaria de Avaliação e Gestão da Informação. Relatório de Pesquisa: estudo qualitativo para avaliação do Programa de Erradicação do Trabalho Infantil (PETI). Brasília, DF: MDS, 2009c. Disponível em: https://bit.ly/3wbAQTp. Acesso em: 31 mar. 2021. 
BRASIL. Ministério do Desenvolvimento Social e Combate à Fome (MDS). Secretaria Nacional de Assistência Social Conselho Nacional de Assistência Social. Sistema Único de Assistência Social. Resolução n. 269, de 13 de dezembro de 2006. Aprova a Norma Operacional Básica de Recursos Humanos do Sistema Único de Assistência Social - NOB-RH/SUAS. Brasília, DF: MDS, CNAS, dez. 2006.

BRASIL. Ministério do Desenvolvimento Social e Combate à Fome (MDS). Secretaria Nacional de Assistência Social. Política Nacional de Assistência Social (PNAS/2004, Norma Operacional Básica NOB/SUAS). Brasília, DF: MDS, 2009d.

COUTO, Berenice Rojas. O Sistema Único de Assistência Social: uma nova forma de gestão da Assistência Social. In: MINISTÉRIO DO DESENVOLVIMENTO SOCIAL E COMBATE À FOME (MDS). UNESCO Concepção e gestão da proteção social não contributiva no Brasil. Brasília, DF: Ministério do Desenvolvimento Social e Combate à Fome, UNESCO, 2009. Disponível em: http://www.mds. gov.br/. Acesso em: 23 abr. 2020. p. 205-2018.

COUTO, Berenice Rojas et al. O Sistema Único de Assistência Social no Brasil: uma realidade em movimento. São Paulo: Cortez, 2010.

PAIVA, Beatriz Augusto de. O SUAS e os direitos socioassistenciais: a universalização da seguridade social em debate. Serviço Social \& Sociedade, [s.I.], n. 87, ano XXVII, set. 2006.

PALOTTI, Pedro Lucas de Moura; COSTA, Bruno Lazzarotti Diniz. Relações intergovernamentais e descentralização: uma análise da implementação doSUAS em Minas Gerais. Rev. Sociol. Polít. Curitiba, v. 19, n. 39, p. 211-235, jun. 2011. Disponível em: http://www.scielo.br/scielo.php?script=sci_arttext\&pid=S010444782011000200015\&lng=en\&nrm=iso. Acesso em: 23 abr. 2020.

TAPAJÓS, Luziele; RODRIGUES, Roberto Wagner da Silva. (org.). Rede SUAS: gestão e sistema de informação para o Sistema Único de Assistência Social. Brasília, DF: Secretaria Nacional de Assistência Social, 2007. Disponível em: http://www.mds.gov.br/. Acesso em: 23 abr. 2020. 